\title{
PENGEMBANGAN INDIGENOUS TOURISM DENGAN PERSPEKTIF DYNAMIC GOVERNANCE (STUDI PADA KAMPUNG HERITAGE KAYUTANGAN KOTA MALANG)
}

\section{DEVELOPMENT MODEL OF INDIGENOUS TOURISM WITH DYNAMIC GOVERNANCE PERSPECTIVE (STUDY IN KAYUTANGAN HERITAGE VILLAGE, MALANG CITY)}

\author{
Ida Ayu Githa Girindra, Muhammad Rifki Alfian Amanulloh, Rizky Dharmawan, \\ Ekky Purnama Sari \\ Fakultas Ilmu Administrasi, Universitas Brawijaya \\ email: Daygitha@gmail.com
}

\begin{abstract}
Abstrak
Kampung Heritage Kayutangan ditetapkan sebagai Kampung Wisata Kota Malang oleh Walikota Malang, sejak 22 April 2018. Penetapan kampung wisata ini merupakan salah satu upaya mewujudkan program "Beautiful Malang". Program ini bertujuan untuk meningkatkan daya tarik wisata Kota Malang serta meningkatkan perekonomian dan mengoptimalkan indigenous tourism Kampung Kayutangan. Kampung Kayutangan memiliki banyak produk wisata yang potensial untuk dikembangkan. Namun, semenjak diresmikan sebagai desa wisata masih belum terlihat dampak yang signifikan terhadap perekonomian. Belum banyak masyarakat yang terlibat langsung dalam pengelolaan dan pengembangan desa wisata ini. Banyaknya jumlah pengunjung tidak diimbangi dengan fasilitas yang memadai. Ini disebabkan kurang terkonsepnya model kampung wisata yang sesuai dengan potensi dan indigenous tourims yang dimiliki. Tujuan penelitian ini untuk: a). Menganalisis Implementasi Dynamic Governance dalam Pengembangan Indigenous Tourism dan menemukembangkan yang relevan dalam Pengembangan Indigenous Tourism di Kampung Wisata Heritage Kayutangan Kota Malang. Penelitian ini menemukan perbedaan model Dynamic Governance yang diterapkan saat ini di Kampung Heritage Kayutangan dengan model Dynamic Governance yang ideal. Berdasarkan perbedaan tersebut maka dikembangkan sebuah Model Dynamic Governance yang relevan dalam Pengembangan Indigenous Tourism dengan mengadopsi model Quadruple Helix di Kampung Heritage Kayutangan.
\end{abstract}

Kata Kunci : Dynamic Governance; Indegenous Tourism; Kampung Kayutangan

\author{
Abstract \\ Kayutangan Heritage Village was established as Malang City Tourism Village by the Mayor of
}


Malang, since 22 April 2018. The determination of this tourist village is one of the efforts to realize the "Beautiful Malang" program. This program aims to increase the tourism appeal of Malang City and improve the economy and optimize indigenous tourism in Kayutangan Village. Kampung Kayutangan has many potential tourism products to develop. However, since it was inaugurated as a tourist village, it has not seen a significant impact on the economy. Not many people are directly involved in management and development of this tourist village. The large number of visitors is not matched by adequate facilities. This is due to the lack of conceptualization of a tourism village model that is in line with the potential and indigenous tourims. The purpose of this study is to: a). Analyze Implementation of Dynamic Governance in Development of Indigenous Tourism and find relevant in Development of Indigenous Tourism in the Heritage Village of Kayutangan Malang. This study found differences in the Dynamic Governance model currently applied in Kayutangan Heritage Village with the ideal Dynamic Governance model. Based on these differences a relevant Dynamic Governance Model was developed in the Development of Indigenous Tourism by adopting the Quadruple Helix model in Kayutangan Heritage Village.

Keywords: Dynamic Governance; IndigenousTourism; Kayutangan Herittage Village

\section{Pendahuluan}

Melalui visi pembangunan "Kota Malang Bermartabat" pemerintahan Kota Malang, menghasilkan sejumlah kebijakan publik pro masyarakat. Kebijakan tersebut khususnya berkaitan dengan program peningkatan kualitas pendidikan dan layanan dasar, program peningkatan produktifitas berdaya saing berbasis ekonomi kreatif, dan mewujudkan kerukunan dan toleransi serta memastikan kepuasan masyarakat. Berkaitan dengan kebijakan peningkatan produktifitas berdaya saing khususnya di bidang pariwisata, Pemerintah Kota Malang melalui peraturan walikota Malang Nomor 15 Tahun 2017 Tentang rencana kerja pemerintah daerah tahun 2018, peraturan ini bermaksud untuk mengembangkan kawasan strategis di kota malang salah satunya kawasan strategis sosial budaya dengan cara menetapkan, mempertahankan, dan merevitalisasi daerah/tempat-tempat yang memiliki nilai sejarah/cagar budaya yang kuat.

Kampung Heritage Kayutangan adalah kampung yang berada di Kecamatan Klojen Kota Malang. Industri jasa kepariwisataan membutuhkan konsep yang jelas agar mampu menjadi sektor andalan bagi daerah di mana program pariwisata akan dikembangkan. Pitana, Gde dan Gayatrin (2005:91) mengemukakan bahwa kegiatan pariwisata sangat kompleks dan merupakan sebuah sistem yang melingkupi berbagai kegiatan atau aktivitas, baik bersifat sosial, ekonomi, politik maupun budaya dan faktor lain.

Berdasarkan SK Walikota Malang, Kampung Heritage Kayutangan ditetapkan sebagai Kampung Wisata Kota Malang yang berlaku mulai 22 April 2018. Penetapan kampung wisata ini merupakan salah satu upaya dalam mewujudkan program "Beautiful Malang” yang dicanangkan oleh Walikota Malang. Tujuan diadakannya program ini salah satunya yaitu 
untuk meningkatkan daya tarik wisata Kota Malang serta meningkatkan perekonomian Kota Malang di sektor pariwisata dan mengoptimalkan indigenous tourism Kampung Kayutangan.Kampung Kayutangan sebagai kampung wisata memiliki banyak produk wisata yang potensial untuk dikembangkan.

Namun, semenjak diresmikan sebagai desa wisata pada tahun 2018 masih belum terlihat dampak yang signifikan terhadap perekonomian di daerah tersebut.Belum banyak masyarakat yang terlibat langsung dalam pengelolaan dan pengembangan desa wisata ini.Sebagian besar dari mereka masih bersifat pasif dan belum digerakkan secara optimal.Dilihat dari jumlah pengunjung menurut data yang dilansir dari Malangtimes yaitu lebih dari 100 pengunjung perharinya saat weekend.Hal ini harusnya yang menjadi motivasi masyarkat untuk lebih giat mengembangkan atraksi dan fasilitasyang tersedia di Kampung Kayutangan yang potensial dijadikan sebagai produk desa wisata sangat beragam.

Padahal seharusnya konsep wisata heritage dan edukasi menjadi daya tarik yang harus dimaksimalkan walaupun dalam pengelolaannya sudah menerapkan tiket yang masih sederhana dan swadaya masyarakat sendiri. Kemampuan dinamis pengelola pariwisata dalam pengembangan yang dilakukan kurang maksimal. Hal ini terlihat dari belum meratanya pemahaman peran sebagai pelaku wisata di Kampung Heritage Kayutangan yang membutuhkan pelayanan pariwisata yang baik.

Keberhasilan pengembangan pariwisata dengan menyesuaikan berbagai kebutuhan masyarakat di masa depan dan perbaikan akan permasalahan serta hambatan yang timbul saat ini akan sangat dipengaruhi oleh kemampuan dinamis dari pihak yang terlibat dalam pengembangan pariwisata Kampung Heritage Kayutangan. Berdasarkan permasalahan yang ada, Peneliti berinisiasi untuk melakukan penelitian terkait implementasi dynamic governance dalam pengembangan desa wisata yang relevan dengan potensi dan local indigenous yang dimiliki oleh Kampung Heritage Kayutangan sebagai upaya peningkatan perekonomian kampung melalui pengembangan wisata yang ada di kampung dengan Konsep indigeneous tourism dan peneliti juga menganalisis model Dynamic governance yang relevan untuk diterapkan dalam pengembangan wisata kampung kayutangan.

Neo dan Chen (2007) menjelaskan konsep Dynamic governance adalah hasil peningkatan kapasitas untuk pembangunan jalur yang adaptif (adaptive path) dan kebijakan yang adaptif (adaptive policy) sehingga dihasilkan eksekusi pengambilan keputusan dari suatu kebijakan yang efektif. Penjelasan lain dari Konsep Dynamic governance adalah institusionalisasi nilai-nilai budaya yang mendukung kemampuan organisasi yang proaktif untuk menghasilkan jalur-jalur yang adaptif (adaptive path). Terdapat tiga konsep penyusun Dynamic governance capabilities, yaitu konsep thinking ahead, thinking again, dan thinking across. Thinking Ahead adalah kemampuan untuk berpikir ke depan, mencakup sejumlah 
dimensi, antara lain: kemampuan mengidentifikasi perkembangan di masa mendatang, kemampuan mengerti implikasi pada kepentingan tujuan sosio ekonomis di masa depan.

Thinking again adalah kemampuan untuk berpikir ulang, mencakup sejumlah dimensi, antara lain; kemampuan berkonfrontasi dengan realita sekarang sehubungan dengan kinerja yang dihasilkan sebagai akibat dari strategi, kebijakan, dan program yang telah dihasilkan, dan kemampuan untuk melakukan desain ulang strategi, kebijakan, dan program yang telah diputuskan agar dapat mencapai kualitas dan hasil yang lebih baik. Thinking across adalah kemampuan berpikir lintas untuk menyeberangi batasan tradisional untuk mempelajari pengalaman orang lain sehingga ide-ide baik dapat diadopsi dan disesuaikan sehingga dapat dihasilkan kebijakan dan program inovatif yang akan diinstitusionalisasikan.

Pariwisata merupakan kegiatan sosial yang melibatkan induvidu atau sekelompok orang yang bertujuan untuk tinggal atau melakukan perjalanan diluar tempat tinggal biasanya untuk jangka waktu tidak lebih dari 12 bulan untuk berbagai kegiatan leisure, bisnis, agama dan alasan pribadi lainnya namun tidak mendapatkan gaji/upah dari perjalanannya tersebut. Aktivitas dari wisatawan tersebut melibatkan dan bersentuhan langsung serta memberi pengaruh terhadap masyarakat setempat (Dorobantu \& Nistoreanu, 2012; Martina, 2014; Pitana \& Diarta, 2009).

Menurut Butler (1999:60), ada enam tahap pengembangan pariwisata yang membawa implikasi serta dampak yang berbeda, secara teoretis, yaitu seperti di bawah ini:

1. Tahap eksplorasi, pertumbuhan spontan dan penjajakan (exploration). Jumlah wisatawan masih sangat sedikit.

2. Tahap keterlibatan (involvement). Promosi daerah wisata dimulai dengan dibantu oleh keterlibatan pemerintah. Hasilnya terjadinya peningkatan jumlah kunjungan wisatawan.

3. Tahap pengembangan dan pembangunan (development). Tahap ini jumlah wisatawan yang datang meningkat tajam.

4. Tahap konsolidasi (consolidation). Tahap ini tingkat pertumbuhan sudah mulai menurun walaupun total jumlah wisatawan masih relatif meningkat.

5. Tahap kestabilan (stagnation). Tahap ini jumlah wisatawan yang datang berada pada puncaknya.

6. Tahap penurunan kualitas (decline) dan kelahiran baru (rejuvenation). Tahap decline, pengunjung kehilangan daerah tujuan wisata yang diketahui semula dan menjadi 'resort" baru.

Dari definisi di atas dapat dipahami bahwa yang dimaksud dengan pengembangan dalam penelitian ini adalah suatu aktivitas memajukan Kampung Heritage Kayutangan dengan menggali berbagai potensi yang bisa dikembangkan menjadi suatu daya tarik wisata 
alternatif. Aktivitas tersebut dikelola oleh masyarakat lokal, ramah lingkungan, berkelanjutan, serta dapat meningkatkan kehidupan sosial budaya dan kesejahteraan masyarakat sesuai dengan pendapat Paturusi (2001) di atas. Menurut Johansena, T. E., \& Mehmetoglu, M. (2011) Secara umum indigenous tourism dikatakan sebagai wisata lokal atau wisata asli daerah tersebut. Dimana dalam indigenous tourism mengandung unsur :

1. Heritage yaitu nilai yang dijaga dan dilestarikan secara turun temurun.

2. History yaitu kondisi pasca terjadinya kontak/ relationship antara masyarakat adat dengan pendatang yang menduduki dan mendirikan pemerintahan di tanah masyarakat adat.

3. Habitat yaitu Keadaan daerah atau lingkungan yang mempengaruhi cara hidup masyarakat.

4. Handycraft merupakan kegiatan seni yang menitikberatkan kepada keterampilan tangan dan fungsi untuk mengelolah bahan baku yang sering ditemukan dilingkungan asal.

\section{Metode Penelitian}

Penelitian ini menggunakan metode penelitian deskriptif dengan pendekatan kualitatif. Definisi pendekatan kualitatif menurut Creswell (2007) dalam Endriani (2015: 37) Penelitian kualitatif merupakan metode-metode untuk mengeksplorasi dan memahami makna yang oleh sejumlah individu atau sekelompok orang dianggap berasal dari masalah sosial atau kemanusiaan. Sedangkan definisi penelitian deskriptif menurut Sugiyono (2009) adalah: penelitian yang dilakukan untuk mengetahui keberadaan variabel mandiri, baik hanya pada satu variabel atau lebih (variabel yang berdiri sendiri) tanpa membuat perbandingan dan mencari hubungan variabel itu dengan variabel yang lain”. Melalui penelitian deskriptif dengan pendekatan kualitatif, peneliti bermaksud untuk menggambarkan secara sistematis, faktual, dan akurat mengenai Implementasi Dynamic Governance Dalam Pengembangan Indigenous Tourism Pada Wisata Kampung Heritage Kayutangan, Kota Malang. Informan dalam penelitian ini adalah Kepala dinas kebudayaan dan pariwisata kota malang, Ketua pengelola wisata kayutangan (pokdarwis), bendahara pengelola wisata kayutangan dan Masyarakat kampung Heritage kayu tangan. Penelitian ini menggunakan metode pengumpulan data kualitatif melalui wawancara mendalam, dokumentasi, studi kepustakaan, dan juga dilengkapi dengan observasi dari kondisi sekitar Kampung Kayutangan. Penelitian ini menggunakan teknik analisis data menurut Miles, Huberman dan Saldana (2014:31-33). Adapun langkah-langkah analisis data sebagai berikut: Kondensasi Data (Data Condensation), Penyajian Data (Data Display), Penarikan Kesimpulan (Conclusions Drawing). 


\section{Pembahasan}

Daerah Kayutangan telah ditetapkan sebagi kawasan wisata budaya (Heritage) oleh Pemerintah Kota Malang. Asal-usul nama Kayutangan menurut kesaksian warga asli Malang yaitu Oei Hiem Hwie dan A. V. Irawan, di sepanjang jalan Kayutangan dulu setiap kanankiri ditanami pohon-pohon yang daunnya berbentuk telapak tangan yang mengembang. Pohon jenis ini juga ditanam di Taman Indrakila tapi kini sudah tidak ada lagi (Widodo dkk, 2006:220). Walaupun pohon legendaris itu sudah tidak bisa ditemui lagi, Kampung Heritage Kajoetangan ini masih menyimpan cagar purbakala atau bangunan bersejarah di Kota Malang. Bangunan-bangunan atau rumah warga ini kental dengan arsitektur kolonial (Belanda). Sepanjang jalan Kayutangan juga merupakan poros ekonomi Kota Malang sejak zaman Belanda sampai sekitar era tahun 1990an. Dalam kampung Kayutangan masih banyak menyisakan kejayaan masa lalu berupa bangunan toko, Makam Eyang Honggo Kusumo, Kuburan Tandak, pasar krempyeng, irigasi Belanda, saluran air, tangga 1000, rumah jaman kolonial dan beberapa spot menarik lainnya. Hal tersebut mempunyai cerita tersendiri dan bisa menjadi komoditi dalam menghadirkan wisata di tengah Kota Malang.

Wahab (2003:6) menyatakan pariwisata budaya adalah perjalanan untuk memperkaya wawasan dan ilmu serta untuk memuaskan kebutuhan hiburan tentang negara lain atau menghadiri pameran- pameran, perayaan-perayaan adat, tempat- tempat cagar alam, cagar purbakala, dan lain-lain. Dynamic Governance dimaksudkan untuk dihasilkan sebuah pemerintahan yang membangun kemampuan secara dinamis (Dynamic capabilities) berupa kemampuan thinking ahead, thinking again dan thinking across.

\section{Thinking abead}

Thinking Ahead adalah kemampuan untuk berpikir ke depan, mencakup sejumlah dimensi, antara lain: kemampuan mengidentifikasi perkembangan di masa mendatang, kemampuan mengerti implikasi pada kepentingan tujuan sosioekonomis di masa depan, serta kemampuan mengidentifikasi investasi strategis dan pilihan yang dibutuhkan masyarakat dalam mengeksploitasi kesempatan baru sekaligus dalam mengurangi efek negatif terhadap potensi ancaman.

a. Inovasi baru dari segi kebijakan

Proses pembaharuan berupa inovasi dari segi kebijakan Merupakan pembaharuan dimana munculnya gagasan-gagasan baru atau sebagai jalan alternatif baru bagi pembuat kebijakan. Gagasan-gagasan baru tersebut telah tertuang didalam visi misi kota malang yang dapat disebut sebagai RPJMD kota malang, dimana didalam RPJMD tersebut mucul sebuah tujuan besar kedepan bagi kota malang, tujuan-tujuan tersebut termuat didalam 6 konsep malang future yang salah satunya 
adalah malang Heritage .

Malang Heritage yang dimaksud adalah konsep wisata Kota Malang yang berbasis wisata bersejarah. Salah satunya wisata Heritage yang dikembangkan Pemerintah Kota Malang adalah destinasi Kampung Heritage Kayutangan. proses memajukan malang Heritage tersebut tidak terlepas pula keikutsertaan warga didalam mengembangkan wisata Heritage. Dikarenakan telah termuat didalam bagian RPJMD kota malang yang berbunyi "mendorong masyarakat sebagai bagian dari kota pariwisata dan pengembangan potensi masyarakat dan nilai ekonomi" .hal ini membuktikan masyarakat ikut terlibat dalam inovasi dari segi kebijakan dengan ikut memajukan potensi lokal berupa pengembangan wisata Heritage Kayutangan.

Thinking ahead tidak hanya berfikir dengan berupa inovasi baru melainkan juga dapat berupa Pencapaian atau taget sasaran dimaksudkan adalah seberapa besar proses perkembangan kampung kayu tangan yang telah dilakukan dalam memajukan 6 konsep sebagai malang future tersebut. Proses perkembangan kampung kayu tangan tersebut terus berjalan dengan diimbangi adanya media sosial sebagai sarana dalam pencapaian target atau sasaran di dalam mengembangkan kampung kayu tangan tersebut.

\section{Thinking again}

a. Melihat proses

Maksud dari melihat proses adalah lebih kepada bagaiamana proses perkembangan secara keseluruhan yang ada didalam konsep malang future tersebut. Dan juga bagaimana kemampuan untuk berpikir ulang, mencakup sejumlah dimensi, antara lain; kemampuan berkonfrontasi dengan realita sekarang sehubungan dengan kinerja yang dihasilkan sebagai akibat dari strategi, kebijakan, dan program yang telah dihasilkan, dan kemampuan untuk melakukan desain ulang strategi, kebijakan, yakni thinking again. Thinking again Lebih terfokuskan kepada Proses perkembagan di kota malang sudah berkembang 17 kampung tematik,yang salah satunya perkembangannya adalah kampung Heritage kayu tangan.

Kampung Heritage kayu tangan sendiri prosesnya sudah sangat cepat, dikarenakan tidak terlepas pula dari peranan media social serta peranan dari manajemen sebagai pendampingan didalamnya, dan juga proses pencapaian pengembangan potensi masyarakatnya. Oleh karenanya prsoes perkembangan kampung Heritage kayu tangan sudah dapat dikatakan sangat cepat didalam mewujudkan destinasi wisata berbasis Heritage .

\section{Thinking across}

a. Penyesuaian (sosialisasi kebijakan kepada public terhadap kebijakan baru) 
Thinking across adalah kemampuan berpikir lintas untuk menyeberangibatasan tradisional untuk mempelajari pengalaman orang lain sehingga ide-ide baik dapat diadopsi dan disesuaikan sehingga dapat dihasilkan kebijakan dan program inovatif. Dalam memperlajari pengalaman orang lain sehingga ide-ide baik dapat diadopsi maka butuh Penyesuaian atau sosialisasi kebijakan baru yang dimaksudkan adalah berupa pemberian informasi-informasi terbaru terkait sebuah kebijakan yang ada kepada public dalam artian adalah warga / masyarakat setempat.

Kegiatan pemberian berupa informasi terkait kebijakan baru khususnya kampung kayu tangan sudah dilakukan oleh dinas pariwisata. Kegiatan pemberian informasi tersebut berupa diskusi rebo'an,diskusi rebo'an merupakan wadah atau tempat bagi warga khusunya kampung kayu tangan didalam menuangkan aspirasiaspirasi serta ide-ide yang disampaikan kepada dinas pariwisata, tidak hanya itu saja diskusi rebo'an juga di gunakan pula sebagai pemberian informasi-informasi dari dinas kepada warga terkait kebijakan yang baru.

Oleh karennaya diskusi rebo'an di kampung kayu tangan sangat diperlukan disebabkan sebagai penjebatanan informasi kebijakan dari dinas terhadap warga kampung kayu tangan.

b. Evaluasi dan belajar Bersama

Thingking across juga dapat berfikir lintas batas dan tidak hanya itu saja melainkan juga Evaluasi dan belajar Bersama menjelaskan adanya bentuk belajar bersama dalam artian sebagai adanya bentuk kerja sama yang dilakukan oleh pemerintah dan juga warga kayu tangan dalam memajukan potensi yang ada.

Dalam evaluasi dan belajar Bersama atau juga dapat dikatakan sebagai bentuk kerja sama, kampung kayu tangan sudah menjalin kerja sama seperti dari pihak akademsi, pihak bank BRI dan juga warga kampung kayu tangan itu sendiri. Dalam proses kerja sama peranan dari akademsi, pihak bank BRI dan warga kampung kayu tangan telah memberikan kontibusi terhadap proses pengembangan kampungnya dengan membuat berupa peta petunjuk, pemberian dana kas, pembuatan poscat, dan juga kaos serta pelatihan pojok gerabah.

\section{Indigenous Tourism}

Indigenous dapat diartikan sebagai pribumi, keaslian atau yang asli.Secara umum indigenous tourism dikatakan sebagai wisata lokal atau wisata asli daerah tersebut. Dimana dalam indigenous tourism mengandung unsur :

\section{a. Heritage}

Salah satu indikator terbantuknya sebuah indigenous tourism adalah adanya 
Heritage .Heritage adalah sebuah nilai yang dianggap penting dan dijaga oleh masyarakat lalu dilestarikan secara turun temurun. Ada 37 rumah yang memiliki desain asitektur belanda. Tidak hanya rumah, namun juga ada bangunan lain seperti pintu rolak, tangga, aliran sungai dan pasar yang juga dibangun pada masa belanda dan masih berfungsi hingga sekarang.

Kampung kayutangan juga mengembangkan beberapa layanan yang bisa dinikmati oleh wisatawan,seperti atraksi permainan anak-anak, juga disediakan produk-produk makanan yang tentunya bertempo dulu seperti jajanan tradisional. Kampung Heritage memang memiliki keunikan tersendiri, dan tidak mudah ditiru karena terbentuk secara alami melalui waktu.Kampung wisata dengan tema seperti ini memanfaatkan potensi yang dimiliki oleh masyarakatnya untuk menjadi daya tarik bagi wisatawan.

\section{b. History}

History merupakan nilai sejarah atau peristiwa penting yang ada di suatu tempat. Peristiwa penting yang terjadi pada jaman dulu dapat menjadi penyebab suatu tempat menjadi memiliki nilai sejarah. Bila dilihat dari segi geografis batas kota malang yang dulu, kampung kayutangan merupakan titik tengah dari kota malang. Tidak heran bila dulu kampung kayutangan sangat ramai dan padat aktivitasnya karena menjadi titik pusat kegiatan kota. Kampung kayutangan memiliki peranan penting bagi belanda karena menjadi tempat peristirahatan bagi para tentara belanda.

Adanya cerita-cerita tesebut membuktikan bahwa kampung kayutangan kaya akan cerita yang memiliki nilai history di dalamnya. Masyarakat kampung kayutangan sendiri sudah merancang sebuah buku yang berisi kumpulan cerita mengenai sejarah bangunan yang ada di kampung kayutangan serta sejarah mengenai kampung kayutangan itu sendiri. Buku tersebut dapat digunakan sebagai pedoman bagi warga yang menjadi guide untuk wisatawan, sehingga selain berwisata, wisatawan juga mendapat edukasi mengenai sejarah kampung kayutangan.

\section{c. Habitat}

Lingkungan sebuah tempat wisata tentunya harus dipastikan memberikan nuansa yang nyaman bagi wisatawan.Demi kenyamanan wisatawan, warga kampung kayutangan menyediakan sarana dan pasarana yang dapat digunakan oleh wisatawan.Mulai dari tempat ibadah, tempat makan, tempat bersantai hingga kamar mandi.Selain membangun prasarana yang baru, masyarakat kayutangan juga berusaha untuk menjaga lingkungannya agar tetap bersih.Mereka melakukan bersih-bersih rutin secara setiap hari minggu di minggu pertama.

Warga kampung kayutangan juga memiliki pertemuan rutin yang dilakukan 
untuk menampung aspirasi-aspirasi masyarakat dan keluhan yang dialami masyarakat sehingga nantinya hasil diskusi tersebut dapat direalisasikan untuk kepetingan masyarakat juga. Berhubung Kampung Kayutangan masih baru terbentuk, sehingga masih banyak hal yang perlu dikembangkan, banyak fasilitas dan spot yang masih perlu diperbaiki.

\section{d. Handycraft}

Handycraft adalah kegiatan seni yang menitikberatkan kepada keterampilan tangan dan fungsi untuk mengelolah bahan baku yang sering ditemukan dilingkungan asal. Masyarakat kampung kayutangan memproduksi kerajinan berbahan baku gerabah. Bahan yang dipilih adalah gerabah karena harganya yang terjangkau dan mudah untuk didapatkan. Hasil kerajinan tangan warga tersebut dikumpulkan dan dipajang disebuah tempat yang dinamakan pojok gerabah. Kini pojok gerabah menjadi salah satu nilai jual yang menarik wisatawan untuk melihatlihat atau hanya sekedar mengambil gambar.kampung kayutangan juga memiliki galeri seni lukisan yang ada di beberapa rumah warga.

Kedepannya akan dibuat inovasi-inovasi baru seperti pembuatan kaos oleholeh kampung kayutangan yang saat ini mulai diproduksi oleh beberapa warga namun jumlahnya sedikit. Masyarakat kampung kayutangan masih terus berusaha untuk mengembangkan kreativitasnya melalui peluang dan potensi yang ada.

Berdasarkan hasil analisis diatas maka terdapat perubahan-perubahan yang terjadi.perubahan tersebut berupa adanya konsep quadruple helix. quadruple helix telah banyak digunakan untuk menjelaskan relasi jaringan antar aktor dalam mengembangkan pusat-pusat inovasi tersebut dengan 4 peranan actor-aktor seperti pemerintah, akademisi, pelaku usaha, dan masyarakat.konsep quadruple-helix menurut Afonso, Monteiro, \& Thompson [6] menjelaskan masyarakat dan komunitas adalah diarahkan pada sisi konsumsi teknologi, pengetahuan, barang dan jasa, atau output lainnya dalam ekonomi kreatif.

Actor tersebut dapat memiliki posisi serta kekuatan daya tawar untuk mendapatkan akses terhadap informasi yang berasal dari aktor lainnya dan juga memiliki pengaruh untuk menggiring opini publik terhadap suatu inovasi produk atau jasa atau kebijakan yang ditetapkan oleh pemerintah setempat.Mengingat peran aktor ini dapat mendorong pembentukan lingkungan yang kreatif dan inovatif, maka aktor masyarakat atau komunitas ini dikembangkan dalam konsep quadruplehelix. Di samping keikutsertaan masyarakat dalam aktor - aktor yang terlibat pada interaksi quadruple helix menganut konsep bottom-up melalui partisipasi dari masyarakat. 
Gambar 1

Model Rekomendasi Pengembangan Indigenous Tourism pada Kampung Heritage Kayutangan Dalam Perspektif Dynamic Governance

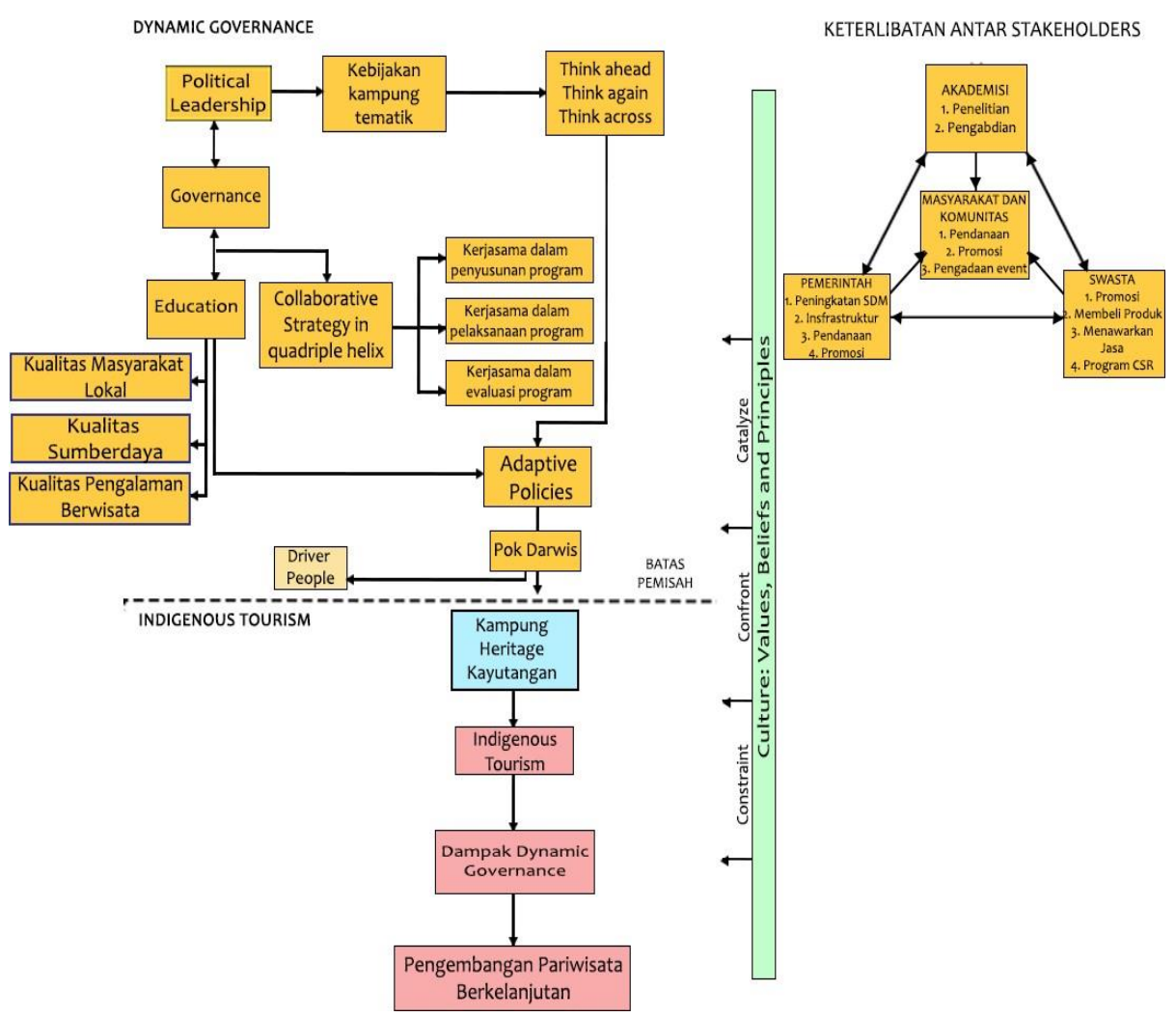

Sumber : Data diolah

\section{Penutup}

Pengembangan indigenous tourism dalam perspektif Dynamic governance visi misi kota malang yang tertuang didalam RPJMD tahun 2018- 2023 merupakan sebuah alternative kebijakan terhadap pengembangan potensi- potensi yang ada di kota malang dimana nantinya dapat memajukan kota malang ke depan. Saran dari penelitian ini adalah Diharapkan dinas pariwisata kota malang lebih memfokuskan kepada pemberdayaan masyarakat tidak hanya pengembangan potensi wisata yang ada di kota malang, dan dalam membuat sebuah kebijakan dinas pariwisata hendaknya lebih mengoptimalkan bagaimana mengelola potensi wisata dan juga pengembangan serta pemberdayaan masyakarat di kota malang.

Model rekomendasi ini tidak jauh berbeda dengan model-model yang telah ada sebelumnya, model rekomendasi ini mengalami sedikit perubahan berupa penambahan seperti edukasi, collaborative strategy in quadruple helix, keterlibatan antar actor, serta 
konsep pengembangan pariwisata berkelanjutan.Edukasi disini merupakan pijakan yang menuju kepada collaborative strattegi in quadriple helix yang menghasilkan tiga aspek. Quadruple helix tersebut merupakan kemitraan atau kerjasama formal, sependapat dengan (Notoatmodjo, 2003: 107).

Kemitraan merupakan salah satu strategi yang digunakan dalam mendukung keberhasilan pengembangan sumber daya maupun kelembagaan, dalam kemitraan dibutuhkan kesepahaman pengelolaan program, kesepahaman pengembangan program antara lembaga yang bermitra hal ini diadopsi dari hasil penelitian Fandri. (2014) tentang Model Kerjasama Antar Stakeholders Dalam Pengembangan Wisata Budaya Dusun Sejo Kabupaten Pasuruan yang sejalan dengan pengembangan pariwisata Kampung Heritage Kayutangan. Sedangkan pengembangan pariwisata berklanjutan disini merupakan output dari keseluruhan model pengembangan di kampung kayutangan yang diharapkan sebagai potensi yang dapat berkembang menjadi pengembangan pariwisata berkelanjutan.

\section{Referensi}

Aas C, Ladkin A \& Fletcher J (2005) Stakeholder Collaboration and Heritage Management. Dalam: DJ Timothy (ed). Managing Heritage and Cultural Tourism Resources: Critical Essays. Farnham: Ashgate. 1-22.

Aat Ruchiat Nugraha, S. P. (2017). MODEL KOMUNIKASI PARIWISATA YANG BERBASISKAN KEARIFAN LOKAL (Studi Deskriptif Kualitatif di Wilayah Lembang Kabupaten Bandung Barat)<http://journals.usm.ac.id/index.php/themessenger/article/view/468>

Afonso, O., Monteiro, S., \& Thompson, M. (2012).A growth model for the quadruple helix. Journal of Business Economics and Management, 13(5), 849-865.

Akwei, Cynthia A. "The Process of Creating Dynamic Capabilities." British Journal of Management. 2008. <http:/www.google.com/search?q=cache:67b1a wz4nugJ:www.som.cranfi eld.ac.uk/som/research/centres/isrc/documents/ TheprocessofcreatingDynamicapabilitiesBJMsubmission30thSeptember.pdf+Dynam ic+capabilities+of+local +government\&hl=id \&ct=clnk\&cd=6\&gl=id $>$.

Aminullah. (2015). Dynamic Governance (Kerangka Konseptual: Melembagakan Budaya, Kapabilitas, dan Perubahan). Jurnal Kebangsaan Volume 9 Nomor 1 Pasuruan : Universitas Yudharta Pasuruan.

Anwar, R. (2009). Pengembangan Model tentang Pengaruh Able People dan Agile $<$ http://lontar.ui.ac.id/file?file=digital/127 934-D+00964+Pengembangan+model.- 
+ HA.pdf $>$

Atmoko, A.W. "Multimetodologi: Jembatan Praksis Ilmu Administrasi." Jurnal Ilmiah Administrasi Publik, Vol. VI, No. 2. Maret- Agustus. 2006.

Arikunto, S. 2010. Prosedur penelitian : suatu pendekatan prakti. ( Edisi Revisi). Jakarta: Rineka Cipta.

Bezza, Bruno. "Dynamic Capabilities, Growth and Long-Term Competitiveness of European Firms: a Diagnosis and The Implications for EU Policies." Faculty of Political Science. D.U. of Industrial Relations University of Florence.

Bappeda Kota Malang. Rencana Pembangunan Jangaka Menengah Daerah (RPJMD) Kota Malang Tahun 2018-2023

Hatfield-Dodds, Steve., Nelson, Rohan., and Cook, David C. "Adaptive Governance: An Introduction, and Implications for Public Policy.” Paper presented at the ANZSEE Conference. Noosa Australia, 4-5 July 2007.

Johansena, T. E., \& Mehmetoglu, M. (2011). Indigenous tourism from a visitor's perspective: an empirical examination of Valene L. Smith's $4 \mathrm{Hs}$ at a Sámi festival in Norway. Journal of Heritage Tourism, 6(2), 129-141.

Neo, Boon Siong., and Chen, Geraldine. (2007). Dynamic Governance - Embedding Culture, Capabilities and Change in Singapore. Singapore: World Scientific Publishing. Co. Pte.Ltd.

Notoatmodjo, Soekidjo. 2003. Pendidikan dan Perilaku Kesehatan, Jakarta : Rineka Cipta

Porter, Michael E. (2007). Dynamic governance (Embedding Culture, Capabilities and Change in Singapore).Singapura : Jurnal World Scientific Publishing Co. Pte. Ltd

Prato.1999.<http://www.google.com/search?q=cache:OTWNM3t2ysQJ:www.lem.sssup.it /Dynacom/files/D18_0.pdf+Dynamic+capabilities+of+local+government\&hl=id\&ct $=\operatorname{clnk} \& \mathrm{~cd}=9 \& \mathrm{gl}=\mathrm{i}>$.

Republik Indonesia. Undang undang Nomor 10 tahun 2009 tentang Kepariwisataan

Rudana, Nyoman. 2008. Strategi Pengembangan Pariwisata Bali. Jakarta: Lembaga Administrasi Negara.

Sugiyono. 2010. Metode penelitian Kombinasi (Mixed Methods). Bandung : Alfabeta. 
Sukardi, 2016. Metode penelitian pendidikan: kompetensi dan praktiknya. Jakarta:PT Bumi Aksara.

Sutopo.2006. Metodologi Penelitian Kualitatif. Surakarta: UNS.

Syafri, Wirman. (2011). Dynamic Governance dan Persfektif Penyelenggaraan

Pemerintahan Daerah http://wirman- syafri.ipdn.ac.id/Dynamic-governance-danperspektif-penyelenggaraan-pemerintahan- daerah/ tanggal 20 Agustus 2019

Tahir, Muchlas M. \& Nahrudin, Zulfan. (2017). Kapabilitas Dynamic governance dalam Optimalisasi pengelolaan lahan terbuka hijau Di kota makassar. Jurnal : Universitas Muhammadiyah Makassar

Teece, D. J. (2009).Dynamic Capabilities and Strategic Management: Organizing for Innovation and Growth. New York: Oxford University Press.

Teece, D.J., Pisano, G and Shuen, A. (1997).Dynamic Capabilities and Strategic Management. Strategic Management Journal, 18, 509-533.

Wahyu, Fandri. (2014). Model Kerjasama Antar Stakeholders Dalam Pengembangan Wisata Budaya Dusun Sejo Kabupaten Pasuruan. Jurnal Administrasi Publik

Weaver D (2010) Indigenous tourism stages and their implications for sustainability. Journal of Sustainable Tourism 18(1):43-60. 